\title{
Effects of Precipitation on Air Pollution in Spring and Summer in Lanzhou
}

\author{
Rui Guo ${ }^{1}$, and Ye Jiang ${ }^{1, *}$ \\ ${ }^{1}$ College of Geography and Environmental Engineering, Lanzhou City University, Lanzhou Gansu 730070, China
}

\begin{abstract}
Using hourly data to study the impact of precipitation on air pollutants and AQI in 2018 spring and summer in Lanzhou. The results show that precipitation has different scavenging capacity for air pollutants. The sorting capacity of precipitation for different pollutants is: $\mathrm{SO}_{2}>\mathrm{PM}_{10}>\mathrm{NO}_{2}>\mathrm{O}_{3}>\mathrm{PM}_{2.5}>$ CO. Different levels of precipitation scavenging capacity is also different, heavy rain and micro rain had the best effect on $\mathrm{PM}_{10}$ removal, moderate rain and micro rain had better wet scavenging capacity for $\mathrm{O}_{3}$. Precipitation duration and precipitation are the key factors of pollutant removal capacity.
\end{abstract}

\section{Introduction}

Meteorological conditions will have a greater impact on air quality[1-3], one of the main factors is precipitation. Previous studies[4-10] have shown that precipitation has a certain scavenging effect on air pollutants. However, due to the limitation of early data, most studies use daily data for analysis, and the pollutants analyzed are mainly $\mathrm{PM}_{10}$, $\mathrm{SO}_{2}, \mathrm{NO}_{2}$ and API. In the first half of 2012, air quality index (AQI) will be used to replace the original air pollution index (API), and the pollutants involved in the evaluation will be increased to $\mathrm{SO}_{2}, \mathrm{NO}_{2}, \mathrm{PM}_{10}, \mathrm{PM}_{2.5}, \mathrm{O}_{3}$, CO.

Lanzhou is one of the most important central cities in the Northwest China, which located in the arid and semi-arid areas of the Loess Plateau, with an annual precipitation of $327 \mathrm{~mm}[11]$. Precipitation is less, so its precipitation scavenging effect must be different from that of more rain water in southern China[12,13]. In this study, precipitation, air pollutants and AQI in Lanzhou in spring and summer of 2018 were taken as the research objects to analyze the effect of precipitation on the removal of air pollutants in this area.

\section{Data and methods}

Precipitation data were collected from China Weather Network and air quality data were collected from Lanzhou air quality real-time release system. As this study did not involve the analysis of the impact of precipitation on sandstorms, so excluding precipitation with sandstorms, excluding incomplete data of precipitation, a total of 2 light rain, 5 light rain( 2 rain for 2 hours, 3 rain for 3 hours or more), 4 moderate rain and 3 heavy rain were collected. The time span is from April 30
2018 to August 20 2018. The classification of precipitation grades is shown in Table 1.

Table 1 Classification of precipitation grades

\begin{tabular}{cccc}
\hline Grade & $\begin{array}{c}\text { Precipitation } \\
\text { range } /(\mathrm{mm} / 24 \mathrm{~h})\end{array}$ & Grade & $\begin{array}{c}\text { Precipitation } \\
\text { range } /(\mathrm{mm} / 24 \mathrm{~h})\end{array}$ \\
\hline $\begin{array}{c}\text { Micro } \\
\text { rain }\end{array}$ & $0.1-0.19$ & $\begin{array}{c}\text { Moderate } \\
\text { rain }\end{array}$ & $10-24.9$ \\
$\begin{array}{c}\text { Light } \\
\text { rain }\end{array}$ & $0.2-9.9$ & $\begin{array}{c}\text { Heavy } \\
\text { rain }\end{array}$ & $25-49.9$ \\
\hline
\end{tabular}

\section{Results and Analysis}

\subsection{Influence of precipitation intensity on pollutant concentration}

Rainfall events with continuous rainfall of 3 hours or more were selected for analysis. The eligible events included 3 light rains, 4 moderate rains and 3 heavy rains. The concentrations of pollutants and AQI were compared and analyzed by LSD method in 6 hours before, during and 6 hours after rainfall. The proportion of precipitation events in this study was calculated when the concentrations of pollutants or AQI decreased significantly in rain or after rain $(p<0.5)$. The result is shown in Figure 1.

Fig. 1 (A) is the ratio of pollutant concentration and AQI that were significantly reduced comparison between rainfall and 6 hours before rainfall to the number of rainfalls $(p<0.5)$. Taking $\mathrm{SO}_{2}$ as an example, the ratio reached $100 \%$ in light rain, that is, the pollutant concentration and $\mathrm{AQI}$ in the rainfall were significantly lower than before the rainfall in three light rain events. It showed that the effect of light rain on $\mathrm{SO}_{2}$ is obvious, heavy rain and moderate rain are second (Fig. 1 (A, B)). And the scavenging effect of rainwater on $\mathrm{SO}_{2}$ occurs within $3 \mathrm{~h}$, because $\mathrm{SO}_{2}$ concentrations did not differ

*Corresponding author:jiangyen_988@163.com 
between rainfall intensity and duration, either during or after rainfall. In contrast, the shortest duration rainfall is 3h (Fig. 1 (C)).

Heavy rain had the most significant effect on $\mathrm{PM}_{10}$ and $\mathrm{AQI}$, and the concentrations of $\mathrm{PM}_{10}$ and $\mathrm{AQI}$ within and after rainfall were significantly lower than those before rainfall in all of the three heavy rains.

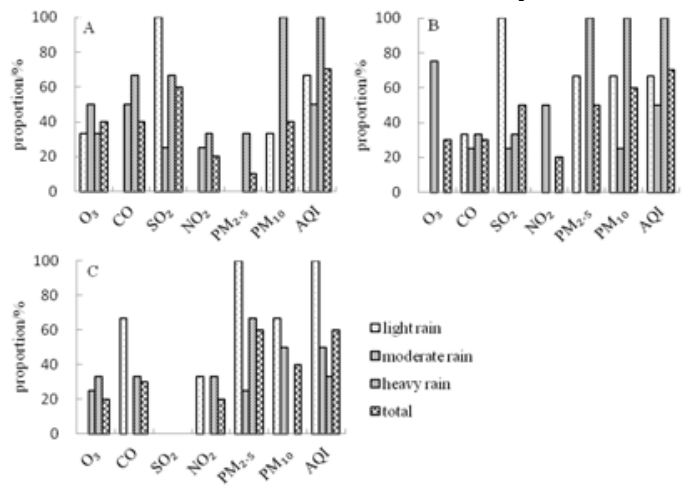

Figure 1 Percentage of precipitation events with significant reduction in pollutant concentration (A: before rain - in the rain; B: before rain - after rain; C: in rain - after rain)

The removal effect of $\mathrm{PM}_{2.5}$ was more significant after rainfall in all rainfall levels. Compared with during the rain, the ratio of after rainfall had a higher proportion. Therefore, the wet removal ability of $\mathrm{PM}_{2.5}$ by rain should have lagging effect.

\subsection{Comparison of wet scavenging capacity of rainfall intensity}

Referring to the studies of Li Rui [14] and Chen Xiaomin [10], $\Delta \mathrm{C}$ was selected to reflect the wet removal ability of rainfall to atmospheric pollutants. The average concentration of air pollutants before 6 hours of a rainfall event was $C_{1}$, the average concentration of air pollutants during the rainfall period was $\mathrm{C}_{2}, \Delta \mathrm{C}_{\alpha}=\left(\mathrm{C}_{1}-\mathrm{C}_{2}\right) / \mathrm{C}_{1} \mathrm{x}$ $100 \%$. The average concentration of air pollutants of 6 hours after the rainfall event was $\mathrm{C}_{3}, \Delta \mathrm{C}_{\beta}=\left(\mathrm{C}_{1}-\mathrm{C}_{3}\right) / \mathrm{C}_{1} \mathrm{x}$ $100 \%, \Delta \mathrm{C}_{\gamma}=\left(\mathrm{C}_{2}-\mathrm{C}_{3}\right) / \mathrm{C}_{2} \times 100 \% . \Delta \mathrm{C}$ is positive, indicating that the concentration of pollutants was decrease, negative indicating the increase of pollutant concentration. The average $\Delta \mathrm{C}$ value of the same grade rainfall reflects the wet removal capacity of the class.

Fig. $2 \Delta \mathrm{C}_{\mathrm{a}}$ was wet scavenging capacity comparison between before rainfall and during rainfall. Among them, the scavenging effect on $\mathrm{SO}_{2}$ was the best. The sorting effect of different types of rainfall was: more than $3 \mathrm{~h}$ light rain $>2 \mathrm{~h}$ light rain $>$ micro rain $>$ heavy Rain $>$ moderate rain. The sorting ability of rainfall to remove pollutants was: $\mathrm{SO}_{2}>\mathrm{PM}_{10}>\mathrm{NO}_{2}>\mathrm{O}_{3}>\mathrm{PM}_{2.5}>\mathrm{CO}$.

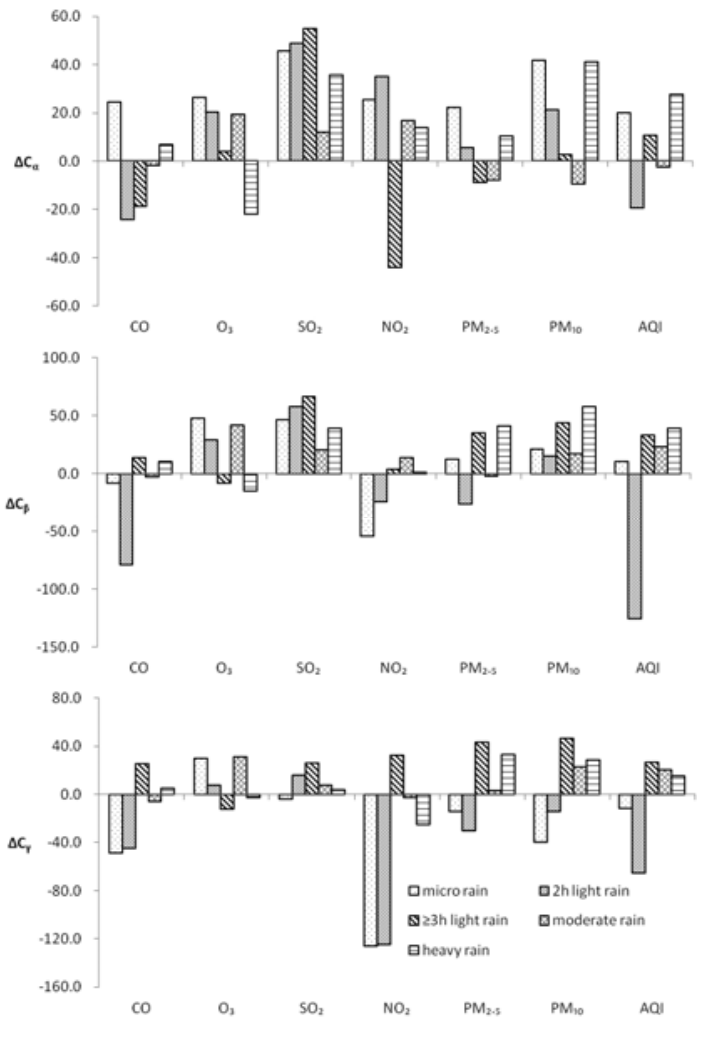

Figure 2 Comparison of wet scavenging capacity of different grades of precipitation

Heavy rain and light rain have the best effect on $\mathrm{PM}_{10}$ removal. But the continuous removal ability of light rain is less than $\geqslant 3 \mathrm{~h}$ light rain and moderate rain(Fig.2 $\Delta \mathrm{C}$ ${ }_{\beta}$ and $\Delta \mathrm{C}_{\gamma}$ ).

The wet scavenging capacity of micro rain and $2 \mathrm{~h}$ light rain to $\mathrm{CO}, \mathrm{NO}_{2}, \mathrm{PM}_{2.5}$ and $\mathrm{PM}_{10}$ was confined to the rainfall process, and the pollutant concentration increased immediately after the rainfall, showing a negative $\Delta \mathrm{C}$ value(Fig.2 $\Delta \mathrm{C}_{\gamma}$ ). Among them, the concentration of $\mathrm{NO}_{2}$ increased the fastest and the $\Delta \mathrm{C}_{\gamma}$ was lower than $-120 \%$.

In the three $\geqslant 3 \mathrm{~h}$ light rain events in this study, the concentrations of $\mathrm{CO}, \mathrm{NO}_{2}$ and $\mathrm{PM}_{2.5}$ increased slightly at the beginning of the rainfall, but decreased first and then increased from the later stage of the rainfall, which indicated that the removal of $\mathrm{CO}, \mathrm{NO}_{2}$ and $\mathrm{PM}_{2.5}$ by $\geqslant$ $3 \mathrm{~h}$ light rain was delayed(Fig. 3).

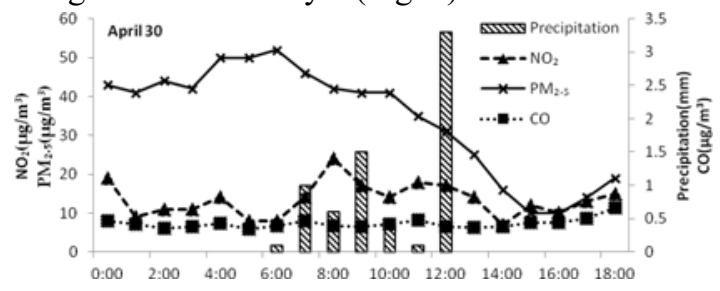




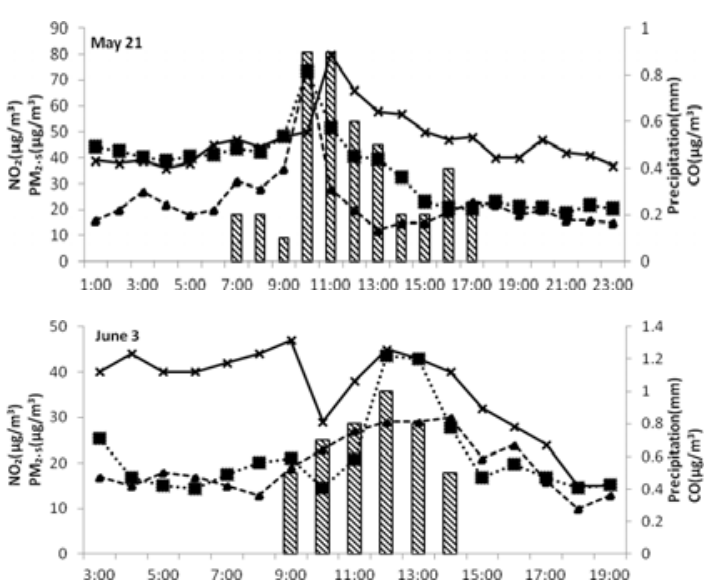

Figure 3 The relationship between $\geq 3 \mathrm{~h}$ light rain and $\mathrm{CO}, \mathrm{NO}_{2}$ and $\mathrm{PM}_{2.5}$

The effect of $2 \mathrm{~h}$ light rain on AQI did not decrease either in rain or after rain, but the AQI value increased.

According to the results of $\Delta \mathrm{C}_{\beta}$ and $\Delta \mathrm{C}_{\gamma}$, the cleaning effect of $2 \mathrm{~h}$ light rain on air quality was the worst, followed by micro rain, and the cleaning effect of $\geqslant 3 \mathrm{~h}$ light rain was the best, followed by heavy rain.

\subsection{The relationship between accumulated rainfall and $A Q I$}

Regression analysis was used to study the effect of rainfall on AQI. The data with rainfall duration of 6 hours or more were selected, including three light rains, two moderate rains and three heavy rains. The independent variable is accumulated rainfall, and the dependent variable is the concentration and AQI value of each air pollutant. The analysis results are shown in Table 2.

Among the 8 rainfall events, except one rainfall model in light rain did not reach the significant level, the other 7 rainfall events all reached the significant level, and the $\mathrm{R}^{2}$ value was higher, indicating that the fitting results were better.

Table 2 Model between accumulated precipitation and AQI

\begin{tabular}{clcc}
\hline $\begin{array}{c}\text { Type of } \\
\text { precipitation }\end{array}$ & \multicolumn{1}{c}{ Model } & $\mathrm{R}^{2}$ & $p$ \\
\hline \multicolumn{1}{c}{$\mathrm{y}=60.16-4.126 \mathrm{x}+1.462 \mathrm{x}^{2}-0.152 \mathrm{x}^{3}$} & 0.702 & 0.250 \\
Light rain & $\mathrm{y}=78.475-25.933 \mathrm{x}+20.984 \mathrm{x}^{2}-3.726 \mathrm{x}^{3}$ & 0.786 & 0.010 \\
& $\mathrm{y}=67.739+2.811 \mathrm{x}-3.258 \mathrm{x}^{2}+0.380 \mathrm{x}^{3}$ & 0.98 & 0.030 \\
\hline $\begin{array}{c}\text { Moderate } \\
\text { rain }\end{array}$ & $\mathrm{y}=77.115-2.733 \mathrm{x}$ & & \\
\hline \multirow{2}{*}{$\begin{array}{c}\text { Heavy rain } \\
\text { He }\end{array}$} & $\mathrm{y}=71.873-1.029 \mathrm{x}$ & 0.688 & 0.041 \\
& $\mathrm{y}=72.675-763+0.093 \mathrm{x}+0.329 \mathrm{x}^{2}-0.004 \mathrm{x}^{3}$ & 0.942 & 0.000 \\
\hline
\end{tabular}

Obviously, there is a linear relationship between AQI and moderate rainfall, and cubic equation can be used to fit between light rain and heavy rain. However, the rainfall at inflection point is not consistent, indicating that there is a threshold for the role of rainfall on air cleaning, but the specific scope needs further study and analysis.

\section{Discussion}

Lanzhou City is located in arid and semi-arid region, with less annual precipitation and shorter rainfall duration. There are few rainfalls for 3 or 4 days, which often occurs in Chongqing [10,13]. Most of the rainfall lasts only a few hours. For example, during the statistical period of this study, 26 precipitations were collected, of which 11 were over 6 hours, 2 were over 12 hours and 0 were over 24 hours. The wet removal capacity of pollutants to pollutants is limited, so hourly data are selected in the study.

It was found that the fitting equation of rainfall and other pollutants reached significant level only in a few precipitations, and the specific mechanism needs further study, so this paper is not listed yet.

In addition, air quality data are affected by many factors, such as rush hours, holidays and working days, seasonal changes, day-night changes and so on. Therefore, a large number of data should be collected to exclude the above factors as far as possible and to conduct comparative analysis of rainfall under the same conditions, which would more likely to reflect the wet scavenging capacity of pollutants.

\section{Conclusion}

Rainfall has different removal effects on different pollutants. The order of removal ability is $\mathrm{SO}_{2}>\mathrm{PM}_{10}>$ $\mathrm{NO}_{2}>\mathrm{O}_{3}>\mathrm{PM}_{2.5}>\mathrm{CO}$, and the wet removal ability of PM2.5 has hysteresis.

Different types of rainfall have different cleaning effects. The cleaning effect of light rain $(\geqslant 3 \mathrm{~h})$ is the best, followed by heavy rain, and that of light rain (2h) is the worst. The $\geq 3 \mathrm{~h}$ light rain had delayed effects on the clearance effect of $\mathrm{CO}, \mathrm{NO}_{2}$ and $\mathrm{PM}_{2.5}$. The sorting of cleaning effect for $\mathrm{SO}_{2}$ is: $\geq 3$ h light rain $>2$ h light rain $>$ micro rain $>$ heavy rain $>$ moderate rain. Moderate rain and light rain have better wet scavenging capacity for $\mathrm{O}_{3}$. Heavy rain and light rain have the best effect on $\mathrm{PM}_{10}$ removal. the wet cleaning capacity of micro rain and $2 \mathrm{~h}$ light rain were limited.

For the improvement of air quality, heavy rain is the best, followed by $\geq 3 \mathrm{~h}$ light rain.

The relationship between light rain, heavy rain and AQI is not a simple linear relationship. There is a clearance limit for the influence of light rain and heavy rain on air quality. After exceeding this limit, the change of AQI tends to be gentle, and gradually increases with the end of rainfall.

\section{Acknowledgments}

Financial support from Lanzhou City University's young teachers research funding project (LZCU-QN2017-21). 


\section{References}

1. P. S. Pillai, S. S. Babu, K. K. Atmos. Res. 61, 149 (2002)

2. S. Vardoulakis, P. Kassomenos. Atmos. Environ. 42, 3949 (2008)

3. Y.Q. Wang, X.L. Yang, J. Natl. Dis. 16, 65 (2007)

4. J.Y. Dong, S.G. Wang, K.Z. Shang, J. Arid Land Resour. Environ. 23,43(2009)

5. K.A. Yu, X. Hu, H.H. Xu, J. Zj Univ. 41, 136 (2014)

6. X.F. Zhao, Y.J. Meng, S.Y. Wang, Meteorol. Sci. Technol. 29, 19 (2001)

7. L.H. Han, H.L. Zhang, X. Xiang, P. Zhang, S.Y. Cheng, W. Wei, Environ. Sci. 38, 2211 (2017)

8. Z.F. Zhang, L. Gan, X.P. Ma, H.P. Zhang, J. Qh Environ. 26, 57 (2016)

9. W.M. Jin, Environ. Prot. Sci. 38, 23 (2012)

10. X.M. Chen, Q. Zou, G.B. Zhou, J. Southwest China Norm. Univ. 38, 113 (2013)

11. J.Q. Hu, W.F. Liu, Z.M. Chang, J.X. Zhang, Water Resour. Hydropower Eng. 48, 8 (2017)

12. D.X. Li, S.Q. Xiong, C. Liu, J. Xiong, Chin. Agric. Sci. Bull. 33, 95 (2017)

13. G.B. Zhou, S.G. Wang, X.M. Chen, Environ. Pollut. Control, 9, 112 (2013)

14. R. Li, X. Wang, Desert Oas. Meteorol. 1, 13 (2007) 